\title{
Nurturing social capital in local communities
}

\author{
Sally Denley
}

Sally Denley is a registered social worker. She is employed at Presbyterian Support Upper South Island and was the coordinator for and developed the SAGE programme. Now her current role is full-time social worker with families.

\section{Abstract}

This article describes how Presbyterian Support Upper South Island is providing services that nurture social capital in community settings in North Canterbury.

One such service within the 'SAGE' programme is described. The SAGE programme is a family mentoring service which matches older volunteers with families and is a service that is considered to be responsive and flexible. The interconnected multi-layered approaches within this service nurtures the bridging between individual, family and community environments in a preventative way. The resulting improvements in social connection are small but important steps in strengthening the fabric of local community development and in creating a better sense of belonging for all involved.

\section{Introduction}

The 1980s and 1990s led to radical changes in the family structure and functioning in New Zealand during a period of enormous social and economic change. There is now an increased diversity of family types including more single parents, stepfamilies, foster families, same sex families and increased migrant populations. Due to increasing rates of separation and childbirth outside marriage, rates of sole parenthood have risen significantly in recent decades, and children are being raised in a diverse range of family circumstances (Ministry of Social Development, 2004). Social policy directions are based on assumptions about relationships between the state, individuals and various groups within society. The prevailing political climate and political party values can influence legislation, political policy, government guidelines and distribution of resources. These values and policies can have detrimental effects on families, and needs can be unmet or not given adequate recognition at policy and practice levels (Cheyne, O'Brien and Belgrave, 1997, pp. 44-45). Consequently, many families face a range of complex situations, some of which can be linked to socio-economic disadvantage and reduced levels of social functioning along with the erosion and fragmentation of neighbourhood support networks.

In the context of a fast-moving and ever-changing environment, it is useful within social policy discussion to think of ways to nurture and redevelop family and to promote the value of parenting. A challenge in the early part of the 21st century is to adapt to changes in the fabric of New Zealand society and in the face of those changes to ask, 'how can we go about 
supporting parenting in ways that increase sustainable social connections and how can we nurture social capital in local communities?' This article explores how ideas of social capital are being applied in the activity of a social service agency.

\section{Theoretical framework}

Social capital theory provides a framework for consideration on how communities can work together to identify community issues and to take action on them. Within the concept of social capital emphasis is put on social networks, trust and reciprocity that help to build on the bonding, bridging and linking of social capital (Robinson, 1997, p. 35). A number of New Zealand government ministries have been involved in discussing the value of social capital as a concept as 'networks together with shared norms, values and understandings that facilitate co-operation within or among groups' (Healy, 2005, p. 5).

According to key theorist Robert Putnam, social capital refers to the collective value of all social networks and the inclinations that arise from these networks to do things for each other. He believes that social capital can be measured by the amount of trust and 'reciprocity' in a community or between individuals. Putnam refers to 'bonding' and 'bridging' as two important components within social capital. Bonding refers to the value given to social networks between similar groups of people, while bridging refers to that of social networks between socially similar groups (Wikipedia, 2005, pp. 3-4).

It is important to note the relationship between bridging social capital and bonding social capital. Without bridging social capital, 'bonding' groups can be isolated and disconnected from the rest of society. In isolation they can become detached from groups and bridging must occur for social capital to develop (ibid, p. 9).

A theoretical distinction has been made between social cohesion and social capital. Robinson argues that social cohesion refers to a society in which people work towards common goals and in which diversity is recognised but does not lapse into conflict. According to him, the term social capital refers to 'networks of social interaction, which reinforces social norms, especially trust; these networks enable people to act together to meet shared objectives effectively' (Robinson, 1997, p. 2). Others have noted the connection more explicitly in terms of social capital being a significant factor in enhancing social cohesion.

If social cohesion describes society where different groups and institutions knit together effectively despite differences, then social capital must be one of the key threads which enables this outcome. These elements of voluntary collaboration and trust are inherent features of social capital (Blakeley \& Suggate, 1997, p. 83).

Beddoe and Maidment (2009) note the short-comings of Putnam's analysis on social capital in the following. Firstly, developing social capital is based on the assumption that the majority of people in a community hold particular values and aim in using these values to promote 'good' within society. Secondly, they further highlight that political advocates have valued the significance of Putnam's analysis on social capital because it provides low-cost communitarian solutions to community problems. Finally, they also highlight that others who have critiqued Putnam's work on social capital have noted that the complexity and grimness of people's lives is ignored and the 'feel good factor' associated with Putnam's work is promoted (Beddoe \& Maidment, 2009, p. 109). 
Bryson and Mowbray (2005) argue that the ongoing ideological deployment of 'community' has been joined by that of social capital, with Putnam's stylised generalisations and assumptions readily serving to support established communitarian-focused policy. They note that governments value 'evidence' that points to an enhancement of social capital, therefore suggesting to them that efficient and cost-effective social outcomes can be achieved by fostering social interaction at the local level. Specifically, Bryson \& Mowbray argue that the social capital concept smooths the way for reliance on low-cost (communitarian) solutions, commonly called community strengthening or capacity building (Bryson \& Mowbray, 2005, p. 100). Others go on to note that these solutions fit an ideology of traditional community values which are problematic paradigms of social relationships (Blackshaw \& Long, 2006, p. 246).

Das (2006) offers a class-based critique of social capital, which notes the limits to both working class social capital formation and practices of reciprocity. For Das, the treatment of social capital as a matter of networks and organisations that cut across class and other boundaries is potentially a limiting and conservative approach. He argues that social capital literature reflects the current worldwide neoliberal agenda, e.g. its emphasis on mutual assistance and self-help, which is often reflected and reinforced by NGOs. Das is dismissive of the notion that 'working class people under neoliberal attack can 'bootstrap' themselves up through mutual aid' (Das, 2006, pp. 83-85).

Clearly, social capital has many definitions, interpretations and uses. Whilst providing a framework for building social capital and social cohesion, Putnam's work has some limitations with its generalised assumptions being used to support low-cost communitarian agendas and solutions. It is argued in this paper that the SAGE (mentoring) programme helps to redevelop and nurture social capital and offers opportunities to build social cohesion through redeveloping and strengthening support networks through a variety of means.

\section{Local demographics and needs analysis}

The societal context, population growth and social change in which Presbyterian Support Upper South Island (Presbyterian Support) developed the SAGE mentoring service is worth noting. The service operates in the North Canterbury region, an area that comprises the Waimakariri and Hurunui Districts. Since 1991 the township of Woodend and its surrounds has been one of the most rapidly changing areas in the Waimakariri District. Between 1991 and 1996 the area's population increased by some 330 people, or 27\%. Between 1996 and 2001 there was an increase of 678 people, or $43 \%$. Current projections indicate that the population of Woodend, and for Waimakariri as a whole, can be expected to continue to experience growth over the next decade (Woodend Profile, 2007). Such rapid growth is likely to require communities to focus on ways to ensure that the sense of community keeps pace with population demands and environmental changes.

Two reports prepared in 2006 reflect some of the pressures experienced within the district. The Waimakariri District Community Needs Analysis (WDCNA) document (2006), and the Waimakariri Local Services Mapping Report (2006) prepared by the Ministry of Social Development, identified the following needs within the North Canterbury community:

- The ability of parents to effectively care for their children. 
- Provide support for parents.

- Create links with families in need of support or advice to more effectively care for their children.

- Implement programmes to address violence, abuse and neglect within family settings.

- Ensure the cost of rental homes for families are not impacting on the families' overall standard of living (Ministry of Social Development, 2006).

Further relevant research provided by 'Whatsup 0800', a counselling telephone service, identifies some wider national issues for children and adolescents. The highest percentage of calls to Whatsup 0800 were around relationships and school-related issues. In particular, these were to do with peer relationships, difficulties maintaining relationships, frequent family conflict and family breakdown such as separation and divorce. This clearly highlighted the need for purposeful connections (Whatsup, 2007).

Two of Presbyterian Support's own research projects identified similar issues to the 'Whatsup' research, with the first seeking to investigate youth anger and how it could be addressed (Milligan, 2007). Youth anger was identified as being about issues that young people experience in their environment, with the research findings showing that involving people from a young person's environment (such as those in their family or school) increased the likelihood of successful interventions (Milligan, 2007).

The second research project was commissioned by the Shirley-Papanui Community Board to ascertain the social and recreational needs of the Mairehau area of Christchurch, and was undertaken by Presbyterian Support staff. The analysis included examining census data, talking with people at people 'hubs', conducting focus groups with adolescents at schools and carrying out a postal survey. The research noted that a number of respondents spoke of a lack of social contact, connection and participation in the community. Teenagers were viewed as the group least well catered for and several respondents felt the relationship between the high school and the community could be enhanced (Milligan \& Jillings, 2006).

The issues identified in the foregoing research are similar to those that are apparent in North Canterbury. From the increase in referrals to Presbyterian Support for support around parenting, there were clearly issues around relationship conflict within families, and concern of children and adolescents being stood down or excluded from their school due to behavioural reasons. Often families were feeling disconnected and isolated from their community. As a response to the above research needs analysis and combined with its own service delivery knowledge of community needs, Presbyterian Support became involved in developing the SAGE programme in North Canterbury.

\section{SAGE programme}

The development of the SAGE (family-mentoring) programme began in 2006 at Presbyterian Support in North Canterbury. A contract for the programme was agreed and funding provided from the Ministry of Social Development. The aim was 'to provide a mentoring programme and recruit older volunteers from the community to mentor families who require support'. Presbyterian Support saw the SAGE mentoring concept as fitting well within its voluntary base, and its aspirations to promote intergenerational connections as part of being in a community. The organisation has been providing community services in North Can- 
terbury since 1999, many of these with the assistance of volunteers. A dedicated volunteer coordinator who had been in the post for a number of years preceding the SAGE programme meant that there was a well-organised volunteer programme with over 100 volunteers. The majority of Presbyterian Support's volunteers are older, retired people who have the time and energy to give back to the community. It was this group of existing volunteers that was originally introduced to the idea of the SAGE programme.

The focus of the SAGE programme was to ensure older community members (or Sages) were involved in the community, that they were valued for their experience and expertise, and to have them engaged with families to share knowledge and skills through narrative and role-modeling. These aims embraced Presbyterian Support's belief that interconnectedness and a range of reciprocal relationships will reduce the level of isolation and lack of social connection that some families experience, and help create sustainable friendship and support networks. 'People helping people' is the organisation's by-line. Sages offer three hours of their time (and often more) per week with their families through home visits. The monitoring and accountability of the Sages' role is managed through a process of individual and group supervision. The other purpose of supervision is to continue the nurturing of existing Sages that encourage further social connection between them. The programme has been in place for several years, where the Sages are mentoring within family homes and partnerships are evolving between Sages and families.

Sages are sharing their life experiences and skills with the families and finding new meaning and purpose in doing that. In turn the families are learning valuable skills to help meet their identified needs. These include parenting skills, problem-solving skills, creating safety and well-being, and the examining of values and beliefs that influence attitudes and behaviours. The development of social support networks between Sages and families has many dimensions as both become part of new support networks that connect or 'bridge' individuals and groups from previously separate parts of the community (i.e. younger and older generations).

Within Presbyterian Support's organisational framework, the achievement of better social connections, enhanced quality of life (safety, well-being and security) and improved social functioning are the key targets of the Sages when working alongside families. Over the several years that Presbyterian Support has developed the SAGES programme, there have been 40 families involved and 15 Sages in total mentoring the families. In February 2007 a SAGE programme evaluation was undertaken by the coordinator of the programme. Nine Sage mentors and eight client families of European descent took part in the evaluation. These families had been part of the SAGE programme from when the programme was first developed. The evaluation highlighted that overall the SAGE programme is working well. It was found to be successfully meeting the needs of its clients in the following ways:

- Practical skills.

- Emotional skills, identifying dominant values.

- Role-modeling.

- Relationships and communication skills.

Families were asked if they felt isolated prior to their involvement with a Sage. Three quarters of families said they had felt isolated to some extent. We also asked families if they felt 
isolated once a mentor became involved with their family. Sixty-three percent said they did not feel isolated anymore. Twenty-five percent said their isolation had improved and that they felt more supported. Only 13 percent said they still felt a bit isolated. Overall the Sage and family relationship has been a positive one (Denley, 2007).

The importance of evaluating families within their own context and nurturing families within our community is paramount if we want to be effective with the services that we provide. Isaac Prilleltensky's work on early intervention stresses the need for interconnected multi-layered approaches, which includes a focus on the child, parent and family as well as community and society (Michaux, 2003). The SAGE programme adopts this approach by focusing on the following:

- Individual - One-on-one work, listening to their narrative, highlighting their values, beliefs, perceptions, dreams and hopes.

- Family - The social connections that build on similarity, informality and intimacy.

- Group/Networks - Groups of individuals based upon common interests and networks within our community.

- Links - Alliances between individuals, groups and communities with formal power for social development.

The SAGE programme is a place-based model of practice with family. This bonding and bridging work is reinforcing to the parents that they have skills and have something to give back to the community. The SAGE programme service provides a way of actively developing social support by encouraging the development of a partnership between volunteers (Sages) and families. This service offers a positive strategy in supporting parenting. The specific outcome is the development of bridging social capital by building relationships between younger and older generations, with the majority of the families involved in the SAGE programme being solo parents. The service provides home visits as well as practical and emotional support that enables the family to benefit from the formal and informal networks. Initially the relationship begins between the parent and the mentor, with a one-on-one relationship established. Further relationships build between the mentor and others within the family. It is acknowledged that one-on-one relationships may be harder to leverage into community change or large-scale action. However, it is through one-on-one relationships that one might learn new skills, for example, parenting skills. This in turn can make it easier to bring these individuals together into a larger group (Sander \& Lowney, 2006, p. 16).

The social interactions in turn build on networks within the community that are helping to redevelop and nurture social capital. This rebuilding occurs through establishing networks that provide support and a sense of belonging and purpose to parents and those involved with them. These processes of rebuilding are considered to be important (Elliot, 2000).

During the SAGE programme, the Sages have embraced their client families and built healthy relationships with family members. The regular home visits are encouraging the building of strong relationships between Sages and family members which are based on mutual trust and respect. The social activity within the SAGE programme has proven to be useful support to families and contributes to rebuilding social capital. This rebuilding occurs through establishing networks that provide support and a sense of belonging and purpose to families. The parents meet through parent groups and social functions at times throughout the year, enabling contacts to be made and bridges to be built between people. 
Some of the families within the SAGE programme attend a cooking class that is held once a week for six weeks. The adults prepare the meal for their families. While food preparation is taking place with parent/s and a Sage mentor, the children of varying ages are together with several adults (sometimes staff and sometimes other mentors) playing games, doing art work and communicating together. When food is prepared the families sit together and share the food. The purpose behind this venture is to provide ideas to families on how to cook cheap and nutritional meals, to encourage families to sit down together to eat a family dinner and to help build relationships within and between families. This represents a form of bonding social capital in terms of bringing a group of parents together who parent alone. It is also a form of bridging social capital through the linking of individuals (mentors and families) from different class backgrounds.

The reciprocity of trust within the group of families and the mentors is beneficial for both families and mentors, and social ties are further built between the families themselves from this venture of the cooking class. Their sense of belonging increases through building positive relationships with one another and through building their social networks. Some of these families become close personal friends, which further provides opportunities to meet others, and make meaningful connections creating wider networks within the community.

Within the mentoring programme, home visits from Sages provide an effective way to mentor families and is a legitimate role for family support. Sages also encourage families to network with others, which enables them to access community services and resources. This in turn contributes to the development of connections within the community and decreases the level of isolation some families have previously experienced.

\section{Conclusion}

Putnam's work on social capital has received a high profile and has been critiqued by many scholars. The New Zealand Government (alongside others) believes that enhancing social capital is beneficial and encourages social action at a local level. This article argues that a community initiative such as the SAGE programme is an effective way of building meaningful social capital. The programme has brought people together within the community who then work together to address identified problems. Building supportive relationships between mentors and families is a significant factor towards promoting positive parenting skills. Self-esteem and communication skills are two basic tools that families need to develop in order for this to happen. As a result, the SAGE programme has created opportunities for the development of social relationships.

The SAGE programme focuses on working with family members within their family homes. If social capital is to be nurtured, then families need to have the opportunity to develop networks within their communities to use their skills. If these skills are taught in isolation from the community then social capital is unlikely to be developed and nurtured. The SAGE mentoring programme offers the opportunity for families to have a stronger sense of belonging and connectedness within their community, through relationships between themselves and others. This paper has argued that the building of informal and formal networks between families, Sages and others through the voluntary activity provided by the SAGE programme have been important in the building of social capital in the North Canterbury community. 
Acknowledgements. I would like to acknowledge the support and encouragement from Vaughan Milner (psusi $\mathrm{CEO}$ ) who gave his time and energy into my process of writing this article and who reviewed my work to completion. I would also like to acknowledge Sue Milligan (psusi researcher) who helped me collate the SAGE Programme Evaluation that was identified in this article.

\section{References}

Beddoe, E., \& Maidment, J. (2009). Mapping knowledge of social work practice. Melbourne, Cengage Learning.

Blackshaw, T., \& Long, J. (2005). What's the big idea? A central exploration of the concept of social capital and its incorporation into leisure policy discourse. Leisure Studies, 24(3), 239-258.

Blakely, R., \& Suggate, D. (1999). Public policy development. In D. Robinson (Ed). Social policy development. Wellington: Institute of Policy Studies.

Bryson, L., \& Mowbray, M. (2005). More spray on solution: Community, social capital and evidence based policy. Australian Journal of Social Issues, 40(1).

Cheyne, C., O’Brien, M., \& Belgrave, M. (1997). Social policy in Aotearoa - A critical introduction. Melbourne: Oxford University Press.

Das, R.J. (2006). Putting social capital in its place. Retrieved 22 June 2009. http://www.cseweb.org.uk/issue. shtml? $x=545303$

Denley, S. (2007). SAGES research evaluation. Unpublished internal report for Presbyterian Support Upper South Island, Christchurch.

Elliot, B. (2000). Promoting family change: The optimism factor. Australia: Allen and Unwin.

Healey, T. (2005). Social capital: Some policy and research implications. Wellington: Institute of Policy Studies.

Michaux, A. (2003). Moving from our place to your space: Rethinking early intervention with children and families. Sydney. Originally presented at 'The people place partnerships conference'.

Milligan, S. (2007). Youth anger and violence in New Zealand - Service and policy implications and possibilities. Sixth Australian and New Zealand Youth Health Conference - Research into practice, evidence into policy. Unpublished. Retrieved 8 February 2008 from http: / / events.lincoln.ac.nz/youth/programme\% 202007\%20v5.pdf

Milligan, S., \& Jillings, M. (2006). Reinvesting in the social nucleus: Mairehau needs analysis. Christchurch: Presbyterian Support Upper South Island.

Ministry of Social Development. (2004). Research confirms diversity of New Zealand families. Retrieved 20 July 2007 from www.msd.govt.nz / media-information/ press-releases/2004-12-01.html

Ministry of Social Development. (2006). Local Services Mapping (LSM) Report for the Waimakariri District. Wellington.

Robinson, D. (1997). Social capital and policy development. Wellington: Institute of Policy Studies.

Sander, T.H., \& Lowney, K. (2006). Social capital building toolkit. Version 1-2. Saguaro Seminar. Civic Engagement in America, John F Kennedy School of Government, Harvard University. Retrieved 23 June 2009, from http:/ / www.hks.harvard.edu/saguaro/pdfs/skbuildingtoolkitversion1.2.pdf

Waimakariri District Council (2006). Waimakariri District Council Needs Analysis. http:/ / www.waimakariri.govt. $\mathrm{nz} /$ publications / Research\%20and\%20Monitoring\%20Reports/index.htm. Retrieved 08 September 2009.

Whatsup. (N.D). Our service. Retrieved 8 February 2007 from www.whatsup.co.nz/about us/ourservices.html

Wikipedia. (2005). Social capital. Retrieved 31 May 2008 from http:/ / en.wikipedia.org/wiki/socialcapital

Woodend Profile. (2007). Retrieved 6 June 2007 from http: / / www.waimakariri.govt.nz / community / groups / woodend-files/dds-02-07@woodendPopulationProfileforWoodendGrowthStrategy.pdf 